\title{
IS PROFILE ALONE SUFFICIENT TO REMOVE GUTTA-PERCHA DURING ENDODONTIC RE-TREATMENT?
}

S.W. Lee, S.T. Tan, Z.A. Che Ab Aziz. Is profile alone sufficient to remove gutta-percha during endodontic retreatment? Annal Dent Univ Malaya 2005; 12: 1-8.

\begin{abstract}
Thirty extracted mandibular premolars were randomly divided into 3 groups. Canals were cleaned, obturated and the teeth incubated. Guttapercha removal was performed using: Hedström files with xylene (Group 1); ProFile ${ }^{\circledR}$ alone (Group 2) and combination of both (Group 3). Time required to remove the gutta-percha was recorded. Postoperative radiographs were taken. Specimens were split longitudinally and photographed. Amount of gutta-percha left at coronal, middle and apical thirds was calculated by computer (QWIN software) and the photographs were also evaluated visually by two endodontists.
\end{abstract}

Results showed that the combined technique was fastest in removing gutta-percha. Radiographically, more residual was left in Group 2. Although computer analysis also showed more residual was left in Group 2, they were in a small percentage and there were no significant differences ( $P>0.05$, SPSS paired-samples $\mathrm{T}$ test) among groups. Although there were significant differences between the two evaluators in their scoring, both generally agreed (Kappa's analysis $=0.64)$ there was more guttapercha residual in Group 2 compared to Group 3 in the apical thirds.

Although the differences in efficacy of guttapercha removal among these techniques were not significant, the use of ProFile ${ }^{\circledR}$ increased the speed of the procedure. The combined technique showed the most superior efficacy in gutta-percha removal.

Key words: ProFile ${ }^{\circledR}$, re-treatment.

\section{INTRODUCTION}

With the improvement in dental technologies, we are moving towards tooth preservation rather than extraction. Nowadays, root canal treatment is more commonly practice to eliminate and remove microorganisms and infected or necrotic materials from within the root canal thus preserving the tooth. The purpose of the treatment is simple, which is thorough cleaning of the canal system and shaping it to receive a three-dimensional obturation of the entire root canal space (1). Success rates of conventional root canal treatment ranges from 62 -
Original Article

S.W. Lee' ${ }^{1}$ S.T. Tan 1 , Z.A. Che Ab Aziz

${ }^{1}$ Dental Student
${ }^{2}$ Lecturer
Department of Conservative Dentistry
Faculty of Dentistry,
University of Malaya
50603 Kuala Lumpur
Malaysia
Corresponding author - Zeti Adura Che Ab Aziz

$98 \%$ (2), whereas for the re-treatment cases are $74 \%$ (3). Hence, re-treatment is still an option for endodontic treatment failures since more superior techniques and instruments are being introduced every year. Re-treatment requires complete removal of the original root filling, further cleaning and refilling (4). The most common root canal filling material to be removed is gutta-percha (5). Nevertheless, the greatest difficulty in re-treatment is to remove the filling material as it represents a mechanical barrier that often requires time and effort to remove. The success rate of endodontic retreatment has been reported to be directly related to the capacity of removal of not only gutta-percha but also of sealing agents (6). However, it is not usual to have canal walls completely free of debris $(7,8$, 9).

Various techniques have been developed to remove gutta-percha, including heat (10), ultrasonics (11) and the use of stainless steel files with a solvent such as chloroform or halothane (8). Nickel titanium instruments might be more effective in removing gutta-percha during re-treatment since they have high elastic flexibility in bending and torsion and show resistance to fracture $(11,12)$, thus making them more accessible to the apical third of the root canal. Previous researches using ProFile ${ }^{\circledR}$ to remove gutta-percha during re-treatment showed that root filling material was still found in the instrumented canals, including the apical thirds $(7,15,16,17,18)$. It is important to remove all root filling materials to uncover remnants of necrotic tissue and to facilitate access of antimicrobial irrigants and medicaments to all ramifications of the canal system which may be harbouring micro-organisms and infected debris (19).

The purpose of this study was to evaluate the efficiency of the ProFile ${ }^{\circledR}$ in removal of gutta-percha in the root canal especially the hard-to-reach apical 
third of the root canal during re-treatment compared with stainless steel Hedström files with xylene as a solvent. The parameters measured were the amount of residual gutta-percha on the canal walls in the coronal, middle and apical parts and the time required in removing the gutta-percha.

\section{METHODS AND MATERIALS}

\section{PRE-OPERATIVE PREPARATION}

Thirty extracted mandibular premolars with a single patent canal and slight root curvature (less than $20^{\circ}$ ) were selected and stored in $10 \%$ buffered formalin at room temperature $\left(24^{\circ} \mathrm{C}-28^{\circ} \mathrm{C}\right)$. Teeth with observable double curvatures and bifurcating canals were discarded. Calculus on the root surfaces was carefully removed using an ultrasonic scaler (Siemens, Germany) and water spray. Access openings were achieved by sectioning the teeth at the cemento-enamel junction (C.E.J) using a conventional handpiece (KaVo, Germany) with carborundum discs (Bego, Germany) and water spray. After achieving access, a barbed broach (Svenska Dentorama AB, Sweden) was used to extirpate the remaining pulp tissue in the canals. A size $10 \mathrm{~K}$-type file (Svenska Dentorama AB, Sweden) was then placed into the canals until it was visible at the apical foramen to confirm patency. Working length of all sample teeth was established $1 \mathrm{~mm}$ short of this length. To standardize the working length, all the teeth were then flattened at the coronal part of the root using carborundum discs (Bego, Germany) until a working length of 14 mm was achieved.

Custom-made 'tooth-holders' for taking radiographs were made using compound impression material (Harvard Abdruckmasse, Germany) for each prepared sample. The impression material was softened using hot water bath and adapted on a flat surface. Each tooth sample was pressed against the soft compound to make two impressions (in buccolingual and mesio-distal direction). After the compound had hardened, each sample was re-placed on the designated holder to re-check its stability. Each tooth and the compound were labeled using permanent ink (Stabilo, Germany). The holders were then kept away from heat and sunlight to prevent distortion.

Two pre-operative views (bucco-lingual and mesio-distal view) were taken for each sample with a size $15 \mathrm{~K}$-file (Svenska Dentorama AB, Sweden) at the working length $(14 \mathrm{~mm})$ using the custommade tooth holder on the same radiograph. The Xray cone was positioned perpendicular to the tooth. The distance between the X-ray source (Siemens Dentotime with cone model No. 5337480 x 1341) and the tooth sample/radiographic film (Ektaspeed
Plus, Eastman Kodak) was standardized by using an $\mathrm{X}$-ray beam aiming device (locator). The direction of the beam was the same throughout the study. The bucco-lingual and mesio-distal radiographs were taken on the same film using a lead shield to mask the half of the film not to be exposed.

\section{PREPARATION OF TEETH}

After standardizing the working length of all the teeth at $14 \mathrm{~mm}$, the teeth were then prepared using a step-down technique. Firstly the cervical and middle-thirds of the canals were flared using Gates Glidden drills (Dentsply Maillefer, Switzerland) sizes 1 and 2. The apical thirds were prepared with stainless steel K-Files (Sveska Dentorama AB, Sweden), size 15 to size 30 . The master apical file (MAF) was standardized at size 30. Apical flare was achieved by shortening the working length of each successively larger file by $1 \mathrm{~mm}$. The final file used was size 45 at $11 \mathrm{~mm}$. Recapitulation was done with the MAF at the working length $(14 \mathrm{~mm})$ in between the larger files used during the apical flaring. Copious irrigation with $2.5 \%$ sodium hypochlorite (Boots, England) was done between the change of files to remove debris and to prevent the blockage of canals. Cleaning and shaping was considered completed when the canal walls felt smooth and the MAF could reach the working length without any difficulty. A medium-fine finger spreader (Kerr, Italy) could be inserted loosely to within $1 \mathrm{~mm}$ of working length. Canals were then dried using paper points and radiographs were taken again with the MAF at the working length. All preparations were performed by one individual.

\section{Canal Obturation}

The prepared canals were obturated using lateral condensation technique. Prior to sealer placement the canals were dried with paper points (Dentsply Asia, Hong Kong). Roth's sealer (Roth International Ltd, Chicago) was mixed according to the manufacturer's instructions until it could be raised 1 inch off a glass slab. A size 30 gutta-percha cone (Dentsply Asia, Hong Kong) was trimmed to fit the apical preparation at the working length with 'tug back' effect. The canal was lightly coated with Roth's sealer. The excess sealer was removed using a paper point size 25 . The tip of the gutta-percha size 30 was then coated with sealer and placed into the canal at the working length. Accessory gutta-percha points (Dentsply Asia, Hong Kong) were then condensed laterally into the canal using the medium-fine spreader (Kerr, Italy). After obturation, another radiograph was taken for every tooth. The excess gutta-percha at the canal openings was removed using heated $\mathrm{Hu}$ Friedy plugger and vertically condensed. The access opening of all the canals was 
then sealed with zinc oxide eugenol cement (Tremrex Corp, USA). All the specimens were then incubated in the incubator (MEMMERT Gmbh+co.kg, Germany) at $37^{\circ} \mathrm{C}$ in $100 \%$ humidity for 2 weeks.

\section{GUTTA - PERCHA REMOVAL}

After a period of two weeks, the temporary fillings were removed. The teeth were randomly divided into 3 groups for the re-treatment procedure.

\section{Hedström and xylene (Group 1)}

Ten teeth were retreated using Hedström file (Svenska Dentorama AB, Sweden) size 25 with xylene (JT Baker, USA) as solvent. A few drops of xylene were deposited onto gutta-percha using an endodontic syringe (Terumo Corp, Japan). Guttapercha was removed using a reaming motion. A few more drops of xylene were then added if necessary. Upon withdrawal, the file was cleaned with gauze before being reintroduced into the canal. A size 20 Hedström file (Svenska Dentorama AB, Sweden) was used at the apical portion of the canal (10-14 $\mathrm{mm})$. Instrumentation was continued until working length was reached and file flutes were consistently clean on removal. A drop of xylene was then introduced into the canal and paper points (Dentsply Asia, Hong Kong) were used to pick up any dissolved gutta-percha until the canals appeared to be cleaned and no more gutta-percha debris adhered to the paper points. The canal was then irrigated with $\mathrm{NaOCl}$. The time required to remove all the gutta-percha was recorded.

\section{ProFile ${ }^{\circledR}$ alone (Group 2)}

Ten teeth were treated using ProFile ${ }^{\circledR}$ (Dentsply Maillefer, Switzerland) alone. Re-treatment was started with a 0.06 taper, ISO size 30 ProFile $^{\circledR}$ rotating at 300 r.p.m in a crown-down manner. Light apical pulses of pressure were used to work the file apically up to $10 \mathrm{~mm}$ of the canal. Then, a 0.04 taper, ISO size 30 ProFile $^{\circledR}$ was used for the last $4 \mathrm{~mm}$ of the working length. ProFile ${ }^{\circledR}$ (Dentsply Maillefer, Switzerland) was consistently cleaned of filling material every time it was withdrawn. The canal was considered clean when the working length was reached and no more gutta-percha could be seen on the file. The canal was then irrigated with $2.5 \%$ sodium hypochlorite (Boots, England). The time required to finish the procedure was recorded.

\section{ProFile ${ }^{\circledR}$, Hedström and xylene (Group 3)}

Ten teeth were treated in the same manner as in group 2. After instrumenting them with ProFile ${ }^{\circledR}$, a drop of xylene was introduced into the canal. A size 20 Hedström file was used to clean the canal once more until no more debris was found on the instrument upon withdrawal. Paper points were used like in the samples in group 1 to confirm the cleanliness of the canal. The time used for guttapercha removal was recorded. The canal was irrigated with $2.5 \%$ sodium hypochlorite (Boots, England) before re-radiographed.

Radiographs were taken for all the samples using the same method as mentioned above. The cleanliness of the canals was assessed from the radiographs. No attempts were made to reinstrument the canals if any radiopacity was found from the radiographs.

\section{METHODS OF EVALUATION}

\section{Time}

The time required to achieve satisfactory guttapercha removal was recorded using a stopwatch (Nokia 3310). The time commenced from the initial entering of Hedström (Svenska Dentorama AB, Sweden) file or ProFile ${ }^{\circledR}$ (Dentsply Maillefer, Switzerland) into the canal and ending when canals were deemed to be clean.

\section{Radiographic evaluation}

The radiographs which were taken after the gutta-percha removal were independently evaluated by the two operators using radiograph viewing box (SMIC, China). A black cardboard with a window of the size of a periapical film was used to mask the excess light. To enhance the radiographic evaluation the radiographs were examined in a darkened room. The presence or the absence of radiopacity of root filling material was recorded.

\section{Computer Evaluation}

All the tooth samples were grooved mesiodistally with carborundum discs in a slow speed handpiece. A chisel (Wedelstaedt, No. 42) was used to split the teeth along the grooves made. Prior to that mesial and distal view radiographs were taken for each sample. After splitting the teeth, the images of the canal walls were taken using a $1 / 2$ " single CCD colour camera (TK-C1380E3VC) with an Edmund Industrial Optics \& Rainbow Lens for colour video camera (JVC) attached to a macrostand. The enlarged images were then enhanced and recorded using Leica QWIN Lite Software (Leica Imaging Systems Ltd, England). Six images were taken for each tooth, which were the cervical, middle and apical thirds of each half.

The baseline images were calculated using QWIN software. Each area on the captured images was outlined three times using a computer mouse. The selected areas need to be agreed by the two operators before measured. The score acquired, the results from the computer and the time needed for re-treatment were analyzed using the ANOVA t-test to evaluate the significant difference among the 3 groups. 


\section{Visual Evaluation}

The images which were recorded using a $1 / 2$ " single CCD colour camera (TK-C1380E3VC) with an Edmund Industrial Optics \& Rainbow Lens were saved in a CD (Circle data ${ }^{\circ}$ ). Examining the saved images to analyse the quality of filling removal were improved as the images were amplified compared by using direct vision in the laboratory. Two examiners, who were unaware of the origin of the experimental groups, recorded the quality of filling removal from each parts of the root in terms of the presence or absence of filling material which were indicated by the colour of the remaining material. The examiners were calibrated by giving them example images and a score given. They were asked to give one of the following scores: $0=$ no debris, $1=<25 \%, 2=25$ $50 \%, 3=50 \%-75 \%$, and $4=>75 \%$. Interexaminer agreement was tested using statistic Kappa as it incorporates an adjustment for the degree of agreement to be expected purely on the basis of chance.

\section{RESULTS}

The previously determined working length was reached in all the specimens. No breakage of instruments (ProFile ${ }^{\circledR}$ or Hedstrom file) or fracture of a tooth was noted during the re-treatment procedures thus no specimens were discarded for the analysis. However, one 0.04 ProFile $^{\circledR}$ system was deformed during gutta-percha removal probably owing to the overuse of the system. The system was then replaced before completing the procedure. Each group analysed consisted of 20 roots.

Table 1 shows the mean time required for filling material removal from the three experimental groups. The time required to remove the gutta-percha approximately similar in groups 3 (combined) and 2 (ProFile ${ }^{\circledR}$ alone) whereby using Hedström file together with xylene (group 1) seemed to take longer. Statistical analysis showed a significant differences were found between Hedström and ProFile ${ }^{\circledR}$, and Hedström and combined technique $(\mathrm{p}<0.05)$.

Figure 2 is the distribution of the scores given for each method of retreatment within the coronal, middle and apical parts of the root canals examined. Most samples showed residual gutta-percha/ sealer (radiopacity) in the apical region of the canal regardless of the method used to remove the filling material, with most samples from the ProFile ${ }^{\circledR}$ group $(80 \%)$. It also showed the highest percentage of samples with radiopacity at the middle portion of the canals $(40 \%)$ and $60 \%$ of the samples in cervical region. However in the combined technique group, only $10 \%$ of the samples showed residual filling material at the cervical region of the canals although no residual gutta-percha were noticed in the middle part of the canals.

Table 3 shows the percentage of surface area covered by residual gutta-percha calculated using Leica QWIN lite software. It was found that all retreatment techniques left residual gutta-percha except for one sample in Hedström group and two samples in combined group. Although the amount of gutta-percha left in the canals was larger in the ProFile $^{\circledR}$ group, there were no statistical differences among groups. Both the Hedström file and ProFile ${ }^{\circledR}$ groups showed highest percentage of area covered

Table 1. Mean time for gutta-percha removal

\begin{tabular}{lc}
\hline Method & Mean (seconds) \\
\hline Hedström file & $744.50^{*}$ \\
ProFile $^{\circledR}$ & 255.70 \\
Combined & 222.80 \\
\hline
\end{tabular}

"Significant differences $p<0.05$

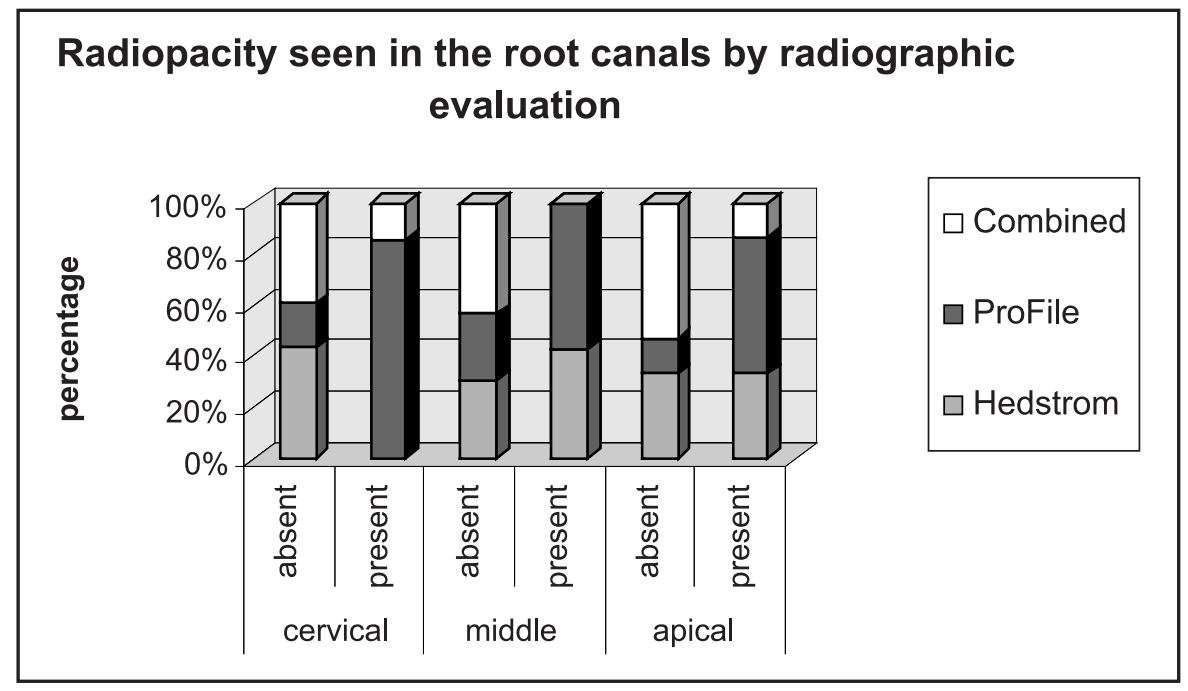

Figure 2: Radiopacity seen in the root canals by radiograph 
Table 2. Radiopacity seen in the root canals by radiographic evaluation

\begin{tabular}{lccl}
\hline & Cervical & Middle & Apical \\
\hline Hedström & $0 \%$ & $30 \%$ & $50 \%$ \\
ProFile $^{\circledR}$ & $60 \% *$ & $40 \% \%^{* *}$ & $80 \%$ ** \\
Combined $^{*}$ & $10 \%$ & $0 \%$ & $20 \%$ \\
\hline
\end{tabular}

* Significant differences $p<0.05$ (Between ProFile ${ }^{\circledR}$ and Hedstöm file, and ProFile ${ }^{\circledR}$ and combined in the cervical portion).

** Significant differences $p<0.05$ (Between ProFile ${ }^{\circledR}$ and combined in the middle and apical portion but there were no significant differences between ProFile ${ }^{\circledR}$ and Hedström file or between combined and Hedström file).

Table 3. Gutta-percha left in the root canals by computer evaluation

\begin{tabular}{lcrr}
\hline & Cervical & Middle & Apical \\
\hline Hedström file & $0.66 \%$ & $3.92 \%$ & $5.27 \%$ \\
ProFile $^{\circledR}$ & $2.58 \%$ & $7.26 \%$ & $11.66 \%$ \\
Combined & $0.81 \%$ & $2.12 \%$ & $1.25 \%$ \\
\hline
\end{tabular}

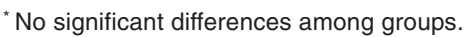

Table 4a. Mean scores given by evaluator 1 in the first evaluation

\begin{tabular}{llll}
\hline Evaluator $1^{* *}$ & Cervical & Middle & Apical \\
\hline Hedström file & 0.05 & 0.15 & 0.40 \\
ProFile $^{\circledR}$ & 0.20 & 0.25 & 0.55 \\
Combined & 0.05 & 0.15 & 0.10 \\
\hline
\end{tabular}

* No significant differences among groups.

Table 4b. Mean scores given by evaluator 2 in the first evaluation

\begin{tabular}{lccc}
\hline Evaluator 2**$^{* *}$ & Cervical & Middle & Apical \\
\hline Hedström file & 1.70 & 1.80 & 2.65 \\
ProFile $^{\circledR}$ & 1.85 & 1.25 & 2.20 \\
Combined & 1.55 & 1.70 & 1.85 \\
\hline
\end{tabular}

*No significant differences among groups.

** Significant differences $(p<0.05)$ between 2 evaluators.

Table 5a. Mean scores given by evaluator 1 in the second evaluation

\begin{tabular}{lccc}
\hline Evaluator $1^{*}$ & Cervical & Middle & Apical \\
\hline Hedström file & 0.05 & 0.35 & 0.45 \\
ProFile & 0.25 & 0.50 & 0.30 \\
Combined & 0.15 & 0.10 & $0.05^{\star}$ \\
\hline
\end{tabular}

"Significant differences $p<0.05$ (Between ProFile ${ }^{\circledR}$ and Combined in the apical portion).
Table 5b. Mean scores given by evaluator 2 in the second evaluation

\begin{tabular}{lccc}
\hline Evaluator 2* & Cervical & Middle & Apical \\
\hline Hedström file & 0.65 & 0.55 & $0.80^{*}$ \\
ProFile $^{\Theta^{*}}$ & 1.10 & 1.00 & 1.25 \\
Combined $^{*}$ & 0.55 & 0.35 & $0.15^{*}$ \\
\hline
\end{tabular}

* Significant differences $\mathrm{p}<0.05$ (Between ProFile ${ }^{\circledR}$ and combined; between Hedström file and combined in the apical portion).

** Between two evaluators

Significant differences $p<0.05$ (Coronal portion of Hedström file technique, ProFile ${ }^{\circledR}$ technique, coronal and middle portion of combined technique).

by gutta-percha in the apical region whereas the combined technique group showed the highest percentage at the middle portion. In total, ProFile ${ }^{\circledR}$ group showed the highest percentage of area in the canals still covered by the residual gutta-percha (total of $21.50 \%$ of surface area) but there were no significant differences among the groups.

Table 4 (a \& b) shows the mean scores given by the two evaluators in the first evaluation whereas the second time evaluation mean scores were as shown in Table 5 ( $\mathrm{a} \& \mathrm{~b}$ ).

There were significant differences between the two evaluators in their scoring of the teeth samples in both the first and second time of evaluation. Both the evaluators reported no significant difference among the groups in their first evaluation but they reported some significant differences among the groups in the second evaluation. In the second evaluation, the first evaluator reported a significant difference between the ProFile ${ }^{\circledR}$ and combined group; Hedström and combined group in the apical portion. The Kappa's test showed that the level of interexaminer agreement calculated was 0.64 .

\section{DISCUSSION}

Root canal retreatment can be assessed in simulated canal; however considerations must also be given to canal irregularities such as fins, because root filling material is more difficult to be removed from these areas. To ensure long term success rate complete cleaning is dependent on effective canal repreparation. Lower premolars with single straight or slightly curved canals were chosen as samples for this study. Single rooted tooth such as mandibular premolars $(7)$, canines $(15,16)$ and maxillary incisors (20) had been used in previous studies. Single canal was easier to be assessed its cleanliness via radiograph or after the tooth was split. The problem with using curved root was the difficulty to obtain symmetrical splitting and if this could not be achieved the unexposed canal areas would be impossible to be examined. 
As it was impossible to standardize the shape of each tooth, a standardized method of root canal preparation was used to reduce the number of variations within root canal system. Crowns were removed in this study, as what had been done by Ferreira et al. (17) and Imura et al.(7) in their studies. This was to standardize the working length of the teeth so that the difference of amount of gutta-percha to be removed will be minimized. All the samples were prepared by the first operator and retreated by a second operator to eliminate any bias. Preparation was done using step down technique only and obturated using lateral condensation technique. Same type of sealer and gutta-percha were used. According to the study conducted by Wilcox \& Swift (21), if the same technique is used for treatment and re-treatment, it is unlikely that previously undebrided areas are completely instrumented during re-treatment. Therefore ProFile $^{\circledR}$ was included as one of the re-treatment technique in this study.

The samples were incubated for only two weeks due to the insufficient time and materials provided. It was presumed that the sealer used in this study was not fully set when the gutta-percha was removed and this could be smeared all over the canal's walls giving false results. Differentiation in between these materials was very difficult in some of the samples thus the scores given by the two examiners may vary widely. This is further supported by a study conducted by Allan et al. (23) whereby after eight weeks of storage at $37^{\circ} \mathrm{C}$ in $100 \%$ humidity incubation of samples, Roth's canal cement was found still not fully set. Since the state of setting of sealers would influence the difficulty of gutta-percha removal and the image evaluation, they should be allowed to be set totally. Incubation done at $37^{\circ} \mathrm{C}$ in $100 \%$ humidity for one year was sufficient to let the sealer set completely (20). Furthermore, sealer was harder to be removed due to its low solubility in organic solvent such as chloroform and halothane (23) although xylene has not been tested on sealer.

Gutta-percha loss during teeth sectioning was another problem encountered. There seems to be no perfect way to prevent gutta-percha loss during sectioning. Some precaution measures however were undertaken to minimize the loss of gutta-percha. Grooves were made on the teeth surfaces along their long axis before they were split by chisel. Prior to that the tooth was embedded in an acrylic. This was done to prevent the teeth from shattering into pieces. In addition, no other rotary or sectioning instrument with water spray or other cooling agents were used. The cooling agent might wash away the residual gutta-percha.

The evaluation of the amount of debris remaining was only possibly be made semiquantitatively. Evaluation was subjective, and observer performance is also known to be variable in many cases whenever diagnosis is required. To standardize scoring as much as possible, the two evaluators (endodontists) were given images of splitted retreated teeth and their expected scoring prior to assessment. The purpose was to derive a common scoring pattern. Interindividual agreement can be increased by examiner calibration (26). The magnitude of kappa calculated showed that 0.64 value obtained represent fair to good agreement beyond chance, as values below 0.40 or so, including negative values may be taken to represent poor agreement beyond chance (28). It could be seen that the significant difference in the scores given by the evaluators had decreased in the second evaluation and would expect a further decrease if there was a third evaluation due to increase of inter-individual agreement through observer calibration (26).

Intra-oral radiograph film used was also not sensitive enough to detect minute gutta-percha residue and sealer. Radiographs are limited to twodimensions. Ideally, three-dimensionally visualization of root canal system would provide better assessment on the distribution of the gutta-percha debris. Results showed that high percentage of radiopacity were noted in all parts of the canals regardless the retreatment techniques used as it is difficult to judge whether the radiopacity was due to gutta-percha or sealer. The presence of residue sealer would gave false radiopacity in the film, especially in the apical region since gutta-percha was more condensed in the cervical and middle part of the canal while more sealer was pushed towards the apex during lateral condensation (15). The use of medical grade mammography film would therefore produce a better result since this type of film had an emulsion coating on only one side and was used with an intensifying screen to produce images of higher resolution and magnification $(17,24)$. Whereas by using computer to calculate the residual areas was more accurate compared to the conventional radiographic method as the residual gutta-percha can be seen more clearly even though only small percentage of gutta-percha present.

However, there was a fair agreement on the presence of the residual gutta-percha when the images of canals examined visually by two endodontists compared to good agreement when the residual gutta-percha was outlined graphically by two operators. This is due to the subjective evaluation on the areas covered either by guttapercha or sealer. Inter-observer variation would also affect the outcome of the result. There was a significant difference between the scores given by the two endodontists. This could be due to the low colour contrast between the remaining gutta-percha and sealer. Furthermore, the percentage range between each score in the scoring system that had been designed was too wide, thus making it not sensitive enough to co-relate with the percentage 
calculated with the QWIN software. The guideline for the scoring system was also set by the researchers. This might increase the inter-observer variation. To overcome this problem, it was suggested specially made gutta-percha was used which had very prominent colour or could take up certain colour staining, thus enhancing the colour difference between the sealer and gutta-percha. The scoring system should also be re-designed to make it more accurate and sensitive.

It was found that all re-treatment techniques left residual gutta-percha all over the canals. Although the gutta-percha left in the canals was more in the ProFile ${ }^{\circledR}$ group, there was no significant difference compared to other groups. Previous study conducted by Barrieshi-Nusair (16) also showed that there was no statistical significance on the effectiveness of removing gutta-percha using ProFile ${ }^{\circledR}$ and stainless steel hand instrument (K-flex). More gutta-percha residue was found in the ProFile ${ }^{\circledR}$ group which may be due to the nature of the ProFile ${ }^{\circledR}$ instrument itself. Owing to the fact that the ProFile ${ }^{\circledR}$ system rotates $360^{\circ}$, it may not be able to adequately clean canal that was not round (15). For mandibular premolars, the shape of the canals might largely affect the ability of the ProFile ${ }^{\circledR}$ to remove the guttapercha. Canals of the mandibular premolars were not always rounding. Ingle (1985) (11) reported that the shape of canals of first mandibular premolars are ovoid at the cervical region, round or ovoid at the mid-root level and round in the apical third region. Weiger et al. (25) also showed that rotary instruments such as Hero $^{\circledR}$ nickel-titanium files could not instrument completely all root dentine walls in the middle third of oval root canals. ProFile ${ }^{\circledR}$ group also showed $60 \%$ of samples with remaining filling material in the cervical part of the canals, which was significant compared to the other two groups. This may also be due to the fact that the cervical region of mandibular premolars is ovoid in shape (11).

All the re-treatment procedures left debris apically than coronally as what have been found in Ferreira et al. (17) and Imura et al. studies (7). This is due to increased anatomical variability and difficulty of instrumentation in this area. This part would be likely infected therefore it is important to be able to remove totally of any existing root canal filling. Thus the use of xylene in the combined technique had increased the effectiveness of this method compared to others.

There was no significant difference between the combined technique and the Profile ${ }^{\circledR}$ alone technique even though the combined technique was faster than the rotary alone. The time for the Hedström and xylene was longer than the combined and Profile ${ }^{\circledR}$ alone technique, as would be expected. The combined technique with xylene significantly quicker $(\mathrm{P}<0.05)$ than Hedström with xylene. The use of ProFile ${ }^{\circledR}$ followed by Hedström file is a time saving procedure which is useful in clinical practice during gutta-percha removal. However, more studies should be done to justify the clinical use of this technique. For a future study, it is suggested to use different techniques in preparing and obturating the canals. This is because nowadays, rotary instrument and thermal condensation in endodontics are getting popular and widely used.

\section{CONCLUSIONS}

Within the limitations of this study, the results imply that the time for gutta-percha removal was significantly faster using ProFile ${ }^{\circledR}$ followed by Hedström with xylene and ProFile ${ }^{\circledR}$ alone compared to Hedström file and xylene. However, the cleaning ability of the three different methods was not significantly different. Nevertheless, the combined technique showed the most superior efficacy in gutta-percha removal.

\section{ACKNOWLEDGEMENTS}

The authors would like to express their gratitude to Mr. Khoo Kok Hwa, Business Operation Manager, Altis-Pro Marketing Sdn. Bhd for his generosity to sponsor the ProFile ${ }^{\circledR}$ (Dentsply Maillefer, Switzerland) for this study and special thanks and appreciation to Dr Mariam Abdullah for her advices and willingness to become one of the evaluators.

\section{REFERENCES}

1. Schilder H. Cleaning and shaping the root canal. Dent Clin North Am 1974; 18(2): 269-96.

2. Sjögren U, Hägglund B, Sundqvist G, et al. Factors affecting the long-term results of endodontic treatment. J Endod 1990; 16: 498504.

3. Sundqvist G, Figdor D, Persson S, Sjogren U. Microbiologic analysis of teeth with failed endodontic treatment and the outcome of conservative re-treatment. Oral Surg Oral Med Oral Path Oral Radiol Endod 1998; 85(1): 8693.

4. Stabholz A, Friedman S. Endodontic retreatment - case selection and technique. Part 2: Treatment planning for retreatment. J Endod 1988; 14(12): 607-14.

5. Friedman S, Rotstein I, Shar-Lev S. Bypassing gutta-percha root fillings with an automated device. J Endod 1989; 12: 432-7. 
6. Wilcox LR. Endodontic retreatment: ultrasonics and chloroform as the final step in reinstrumentation. J Endod 1989; 15: 125-8.

7. Imura N, Kato AS, Hata GI, et al. A comparison of the relative effecacies of four hand and rotary instrument techniques during endodontic retreatment. Int Endod J 2000; 33: 361-6.

8. Wilcox LR. Endodontic retreatment with halothane versus chloroform solvent. J Endod 1995; 21: 305-7.

9. Wilcox LR, Krell KV, Madison $\mathrm{S}$ et al. Endodontic retreatment: evaluation of guttapercha and sealer removal and canal reinstrumentation. J Endod 1987; 13: 453-7

10. Wolcott JF, Himel VT, Hicks ML. Thermafil retreatment using a new "System B" technique or a solvent. J Endod 1999; 25(11): 761-4.

11. Ingle JI. Endodontics, $3^{\text {rd }}$ edition, Philadelphia: Lea \& Febiger 1985; pp144-5

12. Krell KV, Neo J. The use of ultrasonic instrumentation in the re-treatment of a pastefilled endodontic tooth. Oral Surg Oral Med Oral Path 1985; 60: 100-2.

13. Cnalda-Sahli C, Brau-Aguage E, Berasteguijimeno E. A comparison of bending and torsional properties of $\mathrm{K}$-files manufactured with different metalic alloys. Int Endod J 1996; 29: 185-9.

14. Walia H, Brantley WA, Gerstein H. An initial investigation of the bending and torsional properties of Nitinol root canal files. J Endod 1988; 14: 346-7.

15. Baratto Filho F, Ferreira EL, Fariniuk LF. Efficiency of the 0.04 taper ProFile during the re-treatment of gutta-percha-filled root canals. Int Endod J 2002; 35: 651-4.

16. Barrieshi-Nusair KM. Gutta-percha retreatment: Effectiveness of nickel-titanium rotary instruments versus stainless steel hand files. J Endod 2002; 28(6): 454-456.
17. Ferreira JJ, Rhodes JS, Ford TR. The efficacy of gutta-percha removal using ProFiles. Int Endod J 2001; 34(4): 267-74.

18. Valois CRA, Navarro M, Ramos AdA, et al. Effectiveness of the ProFile .04 Taper Series 29 Files in removal of gutta-percha root fillings during curved root canal retreatment. Braz Dent J 2001; 12(2): 95-9.

19. Lin LM, Skribner JE, Gaengler P. Factors associated with endodontic treatment failures. J Endod 1992; 18: 625-7.

20. Bramante CM, Betti LV. Efficacy of Quantec rotary instruments for gutta-percha removal. Int Endod J 2000; 33: 463-7.

21. Wilcox L, Swift M. Endodontic retreatment in small and large curved canals. J Endod 1991; 17 : 313-5

22. Allan NA, Walton RC, Schaeffer MA, et al. Setting times for endodontic sealers under clinical usage and in vitro conditions. J Endod 2001; 27(6): 421-3.

23. Whitworth JM, Boursin EM. Dissolution of root canal sealer cements in volatile solvents. Int Endod J 2000; 33: 463-7.

24. Weiger R, El Ayouti A, Löst C. Efficiency of hand and rotary instruments in shaping oval root canals. J Endod 2002; 28(8): 580-3.

25. Ahmad M, Pitt Ford TR. A comparison using macroradiography of canal shapes in teeth instrumented ultrasonically and by hand. J Endod 1989; 15: 339-44.

26. Reit C. The influence of observer calibration on radiographic periapical diagnosis. Int Endo $\mathrm{J}$ 1987; 20: 75-81.

27. Nguyen NT. Obturation of the root canal system. In: Cohen S, Burns RC, eds. Pathways of the Pulp, $6^{\text {th }}$ edn. St Louis, MO, USA: Mosby Year Book 1994, pp 233.

28. Fleiss JL. Statistical Methods for Rates and Proportions, $2^{\text {nd }}$ edn. New York: Wiley. 